\title{
Acute hepatitis complicating parenteral amiodarone does not preclude subsequent oral therapy
}

\author{
P R James, S M C Hardman
}

Department of Academic and Clinical Cardiovascular Medicine, Whittington Hospital, London, United Kingdom P R James $S$ M C Hardman Correspondence to: Dr James, Department of Academic and Clinical Cardiovascular Medicine, St Mary's Wing, Whittington Hospital, Highgate Hill, London N19 5NF, United Kingdom.

Accepted for publication 24 January 1997
A 50 year old man was admitted with a four week history of increasing exertional dyspnoea and cough productive of white sputum. Two weeks before admission his exercise tolerance had decreased from two miles to 20 yards. He smoked 20 cigarettes a day and drank 60 units of alcohol a week. He was taking no medication.

Initial examination revealed a raised venous pressure, gross peripheral oedema, a smooth tender hepatomegaly (but no cutaneous stigmata of chronic liver disease), a third heart sound, dullness at both bases, and extensive lung crepitations. His pulse was irregular with an apical rate of 160 beats $/ \mathrm{min}$. An admission electrocardiogram confirmed atrial fibrillation with a fast ventricular response rate. His full blood count was normal other than a mean corpuscular volume of $104 \mathrm{fl}$. His $\gamma$ glutamyltransferase was increased at $92 \mathrm{U} / \mathrm{l}$, but other liver function tests and clotting were normal (table). An echocardiogram showed global hypokinesis with left ventricular dimensions of $57 \mathrm{~mm}$ in systole and $63 \mathrm{~mm}$ in diastole.

A diagnosis of alcohol related cardiomyopathy exacerbated by atrial fibrillation was made. Initial treatment with the ultimate intention of establishing sinus rhythm, included intravenous diuretics, heparin, and $1.2 \mathrm{~g}$ amiodarone. The day after admission he had reverted to sinus rhythm but repeat liver function tests revealed a markedly elevated aspartate aminotransferase (AST) of $1356 \mathrm{U} / 1$ and prolonged international normalised ratio of $2 \cdot 5$. The creatinine phophokinase MB isoenzyme was normal at 2 $\mathrm{U} / \mathrm{l}$. No further amiodarone was given intravenously and heparin was withheld until day 5 when his clotting had normalised. An ultrasound examination of the liver showed enlargement with normal echogenicity and no duct dilatation. AST peaked at $8220 \mathrm{U} / 1$ and returned to normal by day 10 (table).
On day 2 he reverted to atrial fibrillation and on day 6 had a cardiac arrest due to ventricular fibrillation, reverting back to atrial fibrillation post defibrillation. Amiodarone was avoided until his liver function tests had normalised; during this time ventricular rate was controlled (70-90 beats/min) with diltiazem. Amiodarone was re-introduced orally on day 11 , using conventional loading doses, without any derangement of liver function. He reverted back to sinus rhythm on day 20 which has been maintained. The patient was discharged home on enalapril, frusemide, amiodarone, and warfarin Seven months later he remained in sinus rhythm on the same medications.

\section{Discussion}

Acute hepatitis following intravenous amiodarone has previously been reported, ${ }^{1-4}$ with the implication that further amiodarone therapy should be withheld. ${ }^{1-3}$ However polysorbate 80 -a component of the diluent used in the intravenous formulation-has been implicated in hepatic toxicity in infants, following intravenous vitamin $\mathrm{E}$ administration which contains both polysorbate 80 and polysorbate $20 .{ }^{5}$ This suggests the hepatic insult may be a function of the diluent rather than the amiodarone. This important distinction would not contraindicate oral amiodarone and was originally suggested by Rhodes et al. ${ }^{4}$

In the present case the combination of atrial fibrillation of relatively recent onset with poor left ventricular function, and an episode of ventricular fibrillation coupled with the potential benefits of restoring and maintaining sinus rhythm, made amiodarone the antiarrhythmic of choice despite the immediate hepatitis. Oral amiodarone was administered as soon as the deranged liver function tests had normalised

\begin{tabular}{|c|c|c|c|c|c|c|c|c|c|c|}
\hline & Admission & Day 1 & Day 2 & Day 3 & Day 4 & Day 5 & Day 6 & Day 8 & Day 10 & $\begin{array}{l}\text { Normal } \\
\text { values }\end{array}$ \\
\hline Bilirubin $(\mu \mathrm{mol} / \mathrm{l})$ & 16 & 53 & 51 & 37 & 51 & 39 & 36 & 32 & 17 & $2-17$ \\
\hline $\begin{array}{l}\text { Aspartate } \\
\text { aminotransferase (U/l) } \\
\text { Alkaline }\end{array}$ & 28 & 1356 & 8220 & 2160 & 860 & 528 & 309 & 117 & 30 & $7-40$ \\
\hline $\begin{array}{l}\text { phosphatase (U/l) } \\
\text { INR }\end{array}$ & $\underset{1 \cdot 2}{62}$ & $\begin{array}{l}62 \\
2 \cdot 5\end{array}$ & $\begin{array}{l}74 \\
2 \cdot 5\end{array}$ & $\begin{array}{l}60 \\
2 \cdot 9\end{array}$ & ${ }^{79}$ & 84 & $\stackrel{77}{1 \cdot 2}$ & $\begin{array}{l}85 \\
1 \cdot 1\end{array}$ & $\begin{array}{l}60 \\
1 \cdot 1\end{array}$ & $\begin{array}{l}25-100 \\
1 \cdot 0-1 \cdot 2\end{array}$ \\
\hline
\end{tabular}

$\mathrm{INR}$, international normalised ratio. 
without recurrence of the hepatitis. This supports the concept that acute hepatitis complicating intravenous amiodarone is related to the diluent rather than the drug. On this basis we suggest amiodarone can be safely administered by the oral route even in patients who develop hepatitis with the intravenous preparation, provided hepatic function is closely monitored.

1 Lupon-Roses J, Simo-Canonge R, Lu-Cortez L Permanyer-Miralda G, Allende-Mondus H. Probable early acute hepatitis with parentral amiodarone. Clin Cardiol 1986;9:225-9.

2 Pye M, Northcote RJ, Cobbe SM. Acute hepatitis after parenteral amiodarone administration. Br Heart $\mathcal{f} 1988 ; 59$ : 690-1

3 Stephenson RNS, Nayam TH, Davies JR. Acute hepatic dysfunction following parenteral amiodarone administration. Postgrad Med F 1989;65:707-8.

Rhodes A, Eastwood JB, Smith SA. Early acute hepatitis with parenteral amiodarone: a toxic effect of the vehicle? Gut 1993;34:565-6.

5 Ruter HD. The E-ferol syndrome solved? In: Dukes MNG, Beeley L, eds. Side effects of drugs, annual 12: a worldwide survey of new data and trends. Amsterdam: Elsevier, $1988: 329$

\title{
IMAGES IN CARDIOLOGY
}

\section{Endothelial dysfunction in the absence of coronary atheroma causing Prinzmetal's angina}

\begin{abstract}
Angiography was performed on a 54 year old woman with no previous history of ischaemic heart disease who was admitted complaining of increasing chest pain occurring frequently at rest. She reported that her symptoms had begun two months previously following withdrawal of hormone replacement therapy (Prempak C; Wyeth, UK) which she had taken for over nine years. An electrocardiogram on admission showed minor inferolateral ST segment depression but later she developed further severe chest pain with $3 \mathrm{~mm}$ of acute ST elevation in leads II, III, and aVF. Urgent cardiac catheterisation was performed within 30 minutes of this episode by which time her pain and electrocardiographic changes had resolved in response to a high dose intravenous nitrate infusion. Angiography revealed completely normal coronaries with a large dominant right coronary artery (fig A) and normal left ventricular function. Subsequent provocation
\end{abstract}

tests involving intracoronary infusion of acetylcholine at concentrations of $10^{-7}$ and $10^{-6} \mathrm{M}$ demonstrated severe diffuse spasm of the right coronary artery with virtual obliteration of the distal branches (fig B). These changes were associated with anginal pain and marked electrocardiographic ST segment depression in the inferior territory. Intravascular ultrasound imaging of the right coronary artery demonstrated that it was free from atheromatous plaque.

These images provide a dramatic illustration of Prinzmetal's angina. Diffuse distal spasm associated with endothelial dysfunction in the right coronary artery were demonstrated in the absence of subangiographic atheroma. It was appealing to speculate that oestrogen withdrawal may have contributed to the evolution of vasospasm in this case.

I D COX J C KASKI
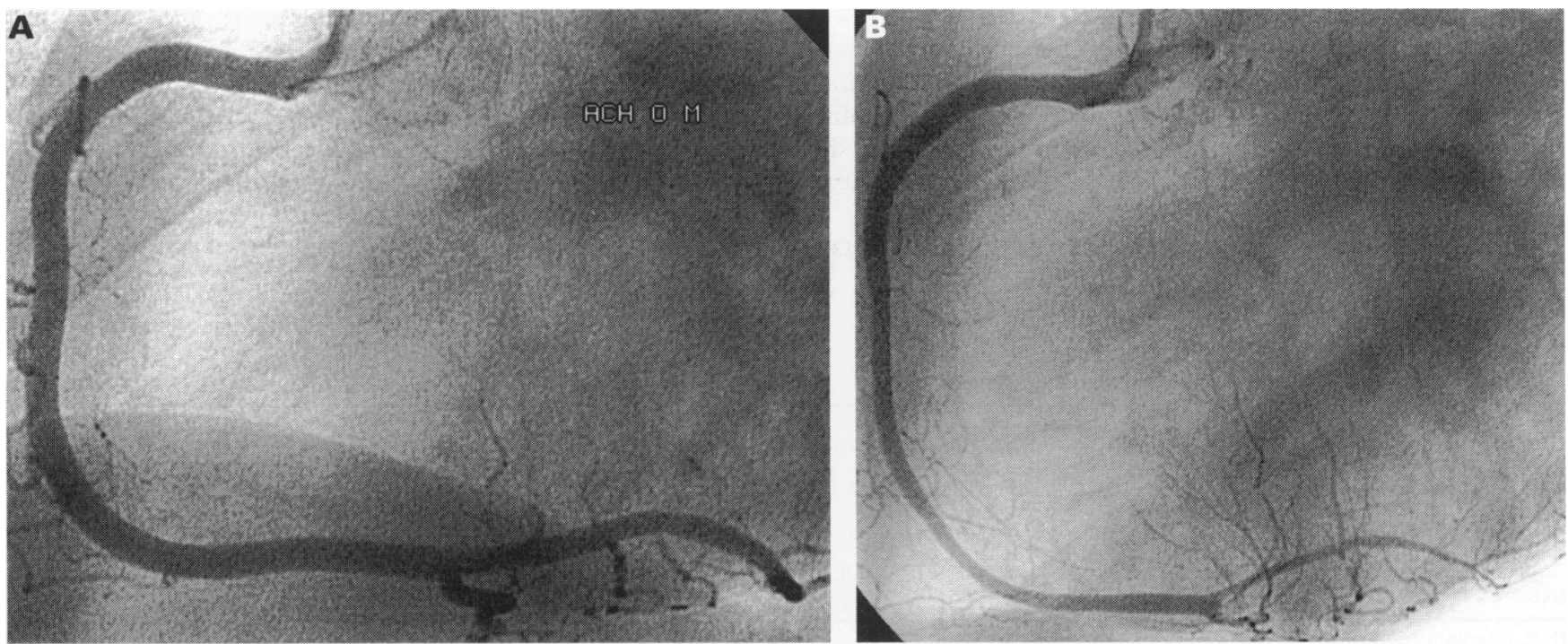